\title{
Heuristic Evaluation of Social Websites: For Blind People
}

\author{
Anam Ashraf and Arif Raza
}

\begin{abstract}
Web usability is a major concern and quite important for everyone, particularly for people with physical disabilities. It is a dilemma that the wider part of websites is not completely usable for blind people. They find difficulty in navigation in web pages and also face difficulty in using social websites. Over the time different usability techniques and methods have been in practice for the improvement of social websites. The main aim of this paper is to identify different usability problems of social websites from the perspective of blind people. Comparative analysis of YouTube and Facebook applications for blind people has been presented in the paper. Usability of these applications is analyzed on the basis of a survey conducted on the blind people. Results gathered after survey highlight the usability issues of two commonly used websites. It has been clearly found that heuristics are the key attribute of software applications and also a good parameter for measuring usability. This paper addresses the social networks usability problems and their evaluation by choosing Jakob Nielsen's ten Heuristics. There is an analysis to improve usability of social websites, by evaluation, comparison and questionnaire results.
\end{abstract}

Index Terms-Heuristic evaluation, mobile government, software quality attributes, web usability.

\section{INTRODUCTION}

A website is usable if it can be used and accessed by all, including people with disabilities [1]. An accessible user interface means that all potential technical restrictions have been eliminated, and thus anyone can easily interact with it. Website usability can be determined by its easiness, user satisfaction impressive functionalities etc. while executing the tasks, such as information finding or completing e-commerce tasks [1]. According to ISO 9241 standard, usability is the "extent to which a product can be used by specified users to achieve specified goals with effectiveness, efficiency and satisfaction in a specified context of use" [2].

It is very essential to keep consideration of usability issues while designing a website, because as with the cutting edge of technology internet usage is growing on rapidly. The website usability basically involves the people, hardware and software to access information from anywhere.

Many conceptual guidelines specifically related to web content and applications have been produced, in order to help developers to create efficient, accessible and usable

Manuscript received May 25, 2013; revised July 29, 2013.

Anam Ashraf is with the Department of Computer Software Engineering, National University of Sciences and T echnology (NUST), H-12, Islamabad, Pakistan (e-mail: anamashraf.mscs19@ students.mcs.edu.pk ).

Arif Raza is with the Department of Computer Software Engineering, National University of Sciences and T echnology (NUST), H-12, Islamabad, Pakistan (e-mail: arif_raza@mcs.edu.pk). applications or products [3]-[6].

As the physical disability is a very critical and sensitive issue, developed countries work a lot for improving web usability. Several countries have to act out laws or guides to promote adoption of specific accessibility (and usability) guidelines [7], [8].

According to many studies, it has been revealed that mostly fully blind people are more affected by the web usability problem rather than people with rest of physical disabilities [9]-[11].

However currently there are many websites e.g. e-learning or social networks that are not easily usable for blind or visually challenged people because of different usability issues.

According to the World Health Organization (WHO), in June, 2012 more than 285 million people worldwide are visually challenged, 39 million are blind and 246 have low vision .More than $82 \%$ of them are 50 years of age \& older and $90 \%$ of the world of visually challenged people live in developing countries. The World Health Organization also esteems at 180 million people that are affected by the visual deficiencies, among which 40 to 45 million are fully blind; these numbers can be doubled in 2020 [12].

There is a need to work on the usability issues of web, and consider heuristic evaluation tenets defined by Jakob Nielsen's ten usability heuristics to improve usability [13]. At this time when technology is rapidly growing and people are using number of technologies to take benefits from them, it is very much essential to keep considering the usability issues. People access different services such as Facebook YouTube, Google etc. from their computers as well as from their pocket pc or mobile cellular phones.

Usability inspection is quite important which is provided by different authorities. It is applied by observing different behavior while using web application or accessing web services accessed through different devices.

Blind people use their mobile phones and other easy to carry devices to access all the computers applications and websites through wireless connection. Usability controls is quite important which will be provided by different authorities and it will be provided by observing different movement on the websites and response towards behavior of user.

The approach used in this research paper is based on websites evaluation by observing behavior of visually challenged people while using the website services.

Evaluation results of websites clearly identify the usability issues and proposed solution will facilitate the users with all requirements related to the website usability, for physical disability of blindness. In particular this approach is based on websites comparison and their evaluation by observing behavior of special people while using particular websites. 
This approach can provide a lot of benefits to those people who suffer from blindness and cannot be facilitated through web accessibility. By using this technique they can come to know about many features of websites and will feel comfort in using cutting edge technology.

In this paper we will discuss different usability perspectives of social websites. We will also analyze and evaluate its usability. Comparative analysis will be discussed on the basis of survey conducted on the blind people.

This paper includes i) related work, ii) comparative analysis of Facebook and YouTube, iii) Findings on the basis of comparison of YouTube and Facebook and iv) conclusion and future work.

\section{RELATED WORK}

Jakob Nielsen [13] proposed ten heuristic to enhance the usability of application. The main idea of the paper revolves around the usability assessment of web accessibility that is mostly used by visually impaired people having physical disability of blindness.

de Mendonça [14] performed a case study for blind users for the accessibility of web services through different devices and also presented prototype; also mentioned about Mobile-government (M-Government) that is done with a lot of work while enhancing the web usability and accessibility for special people.

The design evaluation of most of the applications is done by only consideration of normal people having no disability. Application owners (developers) want only frequent users so they eliminate visually challenged people by considering them infrequent users [14].

Reference [14] shows expressive summarization, usability of web accessibility for people with visual disabilities is deeply explained. They also set fourth fourteen requirements to be taken into account by application designers and developers.

Earlier contributions in this direction are the ones provided by Fair weather et al. [15].

Baxendale [16] clearly stated in his work about heuristic features of text, frequency of words and importance of sentences.

In [17] overview of web accessibility technology has been provided. The focus of research was on page designers to learn about disabilities and to create more usable and accessible web pages at authoring time.

Bolchini et al. [18] discussed about the text, with natural language generation, since it is quite complex problems and solutions are related to the accessibility and application.

Henrik Tonn-Eichstadt [19] dealt with the measuring application usability for visually challenged people. They have worked on accessibility and usability.

\section{COMPARATIVE ANALYSIS OF FACEBOOK AND YouTuBE VIA QUEST IONNAIRE SURVEY}

Our survey was questionnaire based. In our survey, our participants were educated blind people. They all were already using these applications for last 5 years. We requested them to observe the behavior and response of the YouTube and Facebook application deeply for 1 hour and then they filled out two questionnaires to assess the usability of the applications. Our sample size of this survey was 50 .

\section{A. Websites Usability Survey}

The survey was conducted in Islamabad, Pakistan. In Pakistan, we approached an institute called Pakistan Foundation Fighting Blindness (PFFB) and blind students of different universities of Pakistan. However different social groups on Facebook called adult social group for blind or visually impaired and visually impaired support group also helped us a lot while conducting survey.

While performing usability survey following steps were under taken:

- The participants were free to use websites for one hour, to make them more familiar with the usability issues.

- Two questionnaires were prepared against each website.

- Soft copies of two questionnaires were provided to each visually challenged people.

- Questions were asked following Nielsen's ten heuristics.

Optional suggestions were also recorded to know their overall experience of the websites.

- Likert Scale that was provided to student to evaluate the results was:

1) Strongly disagree 12

2) Disagree 3-5

3) Agree 6-8

4) Strongly agree 9 and above

5) Neutral 0

Average of rating from all 50 visually challenged people against each usability heuristics are graphically represented in Fig. 1 and Fig. 2.

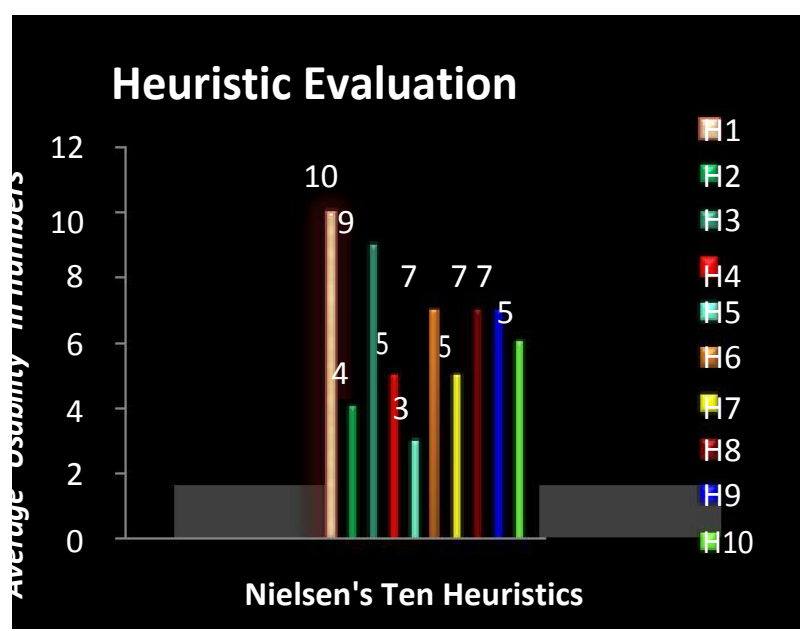

Fig. 1. Usability survey of Facebook.

The above mentioned Fig. 1. shows the average usability of Facebook following the Nielsen's ten heuristics. The figure shows that the average usability of H1 (visibility of system status), H4 (consistency and standards) and H7 (flexibility and efficiency of use) are more than other heuristics of this website.

Fig. 2. shows the average usability of YouTube. It is clearly shown in the figure that usability of heuristics H1 (visibility of system status), H3 (user control and freedom) and H6 
(recognition rather than recall) are greater than other Nielsen's heuristics.

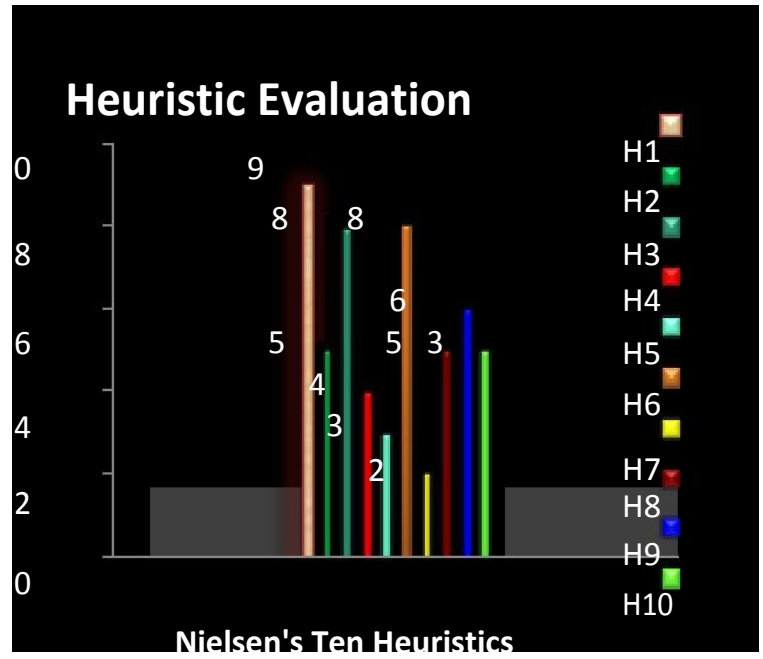

Fig. 2. Usability survey of YouTube

Fig.1. and Fig.2. shows Heuristic evaluation of Facebook and YouTube from the perspective of blind users. It also highlights the problems and the average usability of other heuristics.

Fig.3. highlights the average usability of each heuristic of websites, Facebook and YouTube. It also shows that the majority of participants found the more usability of $\mathrm{H} 1$ (visibility of system status), H3 (user control and freedom), H6 (recognition rather than recall) and H9 (Help users recognize, diagnose and recover from errors) in both the websites.

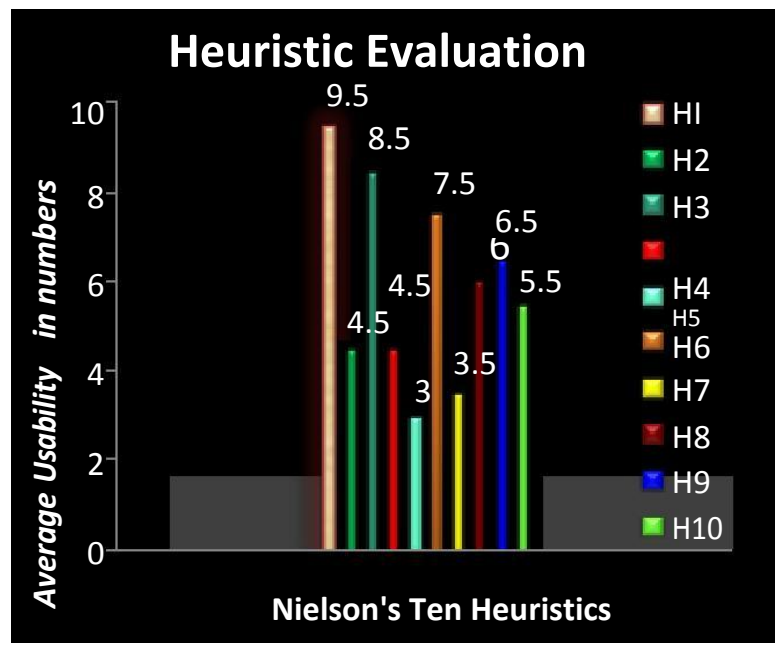

Fig. 3. Average usability of each heuristic for Face book and YouTube.

\section{FINDINGS}

In this Heuristic evaluation of social websites Facebook and YouTube survey, it is found that most of the participants faced problems in heuristic $\mathrm{H} 2$ (Match between system and the real world), H4 (Consistency and standards), H5 (Error prevention) and $\mathrm{H} 7$ (Flexibility and efficiency of use). After performing this survey it has also been concluded that how many different changes that are needed in terms of usability and accessibility of application and in application designs. It is also found that visually impaired people are facing fewer problems while performing normal application tasks like sign in, sign out etc. but found difficulties while accessing different important web applications tasks.

It is also found that visually impaired people are facing fewer problems while using Facebook as compared to YouTube.

Hence it is found that heuristic evaluation is a good rating scale for measuring usability of any application and in this case of social websites. One of the advantages of heuristic usability is that testers can peep and test the usability of their application with limited resources easily by conducting survey or experiment.

By summarizing the above stated comparative analysis results of research work, Fig. 4. depicts the view of average usability of Facebook and YouTube as 54\% and $46 \%$ respectively. Through average usability results, designing and testing teams can make profitable use in social networking websites. These results also provide view for other application related personals for heuristic evaluation, as it is cheap and easy.

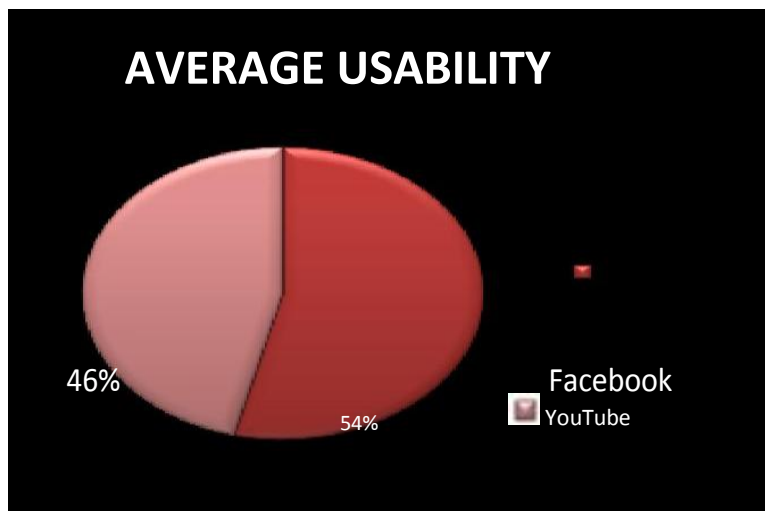

Fig. 4. Overall usability of Facebook and YouTube.

\section{CONCLUSION AND FUTURE WORK}

Usability of social websites and accessing different web application via different devices such as pocket pc, cellular-phone etc. is growing increasingly day by day. This research is basically focused on the usability of social websites that can be used by visually challenged people. For evaluating social websites its usability experimental approach was used. Involvement of special people was made to make it auspicious. By performing this evaluation research, it is concluded that it provides us deep cognition about its different effects, behavior, users, response, frequency of user response etc.

In future we can enhance our work towards the software usability by evaluating usability of these websites through automated tools and by involving field experienced people having disability of blindness during design and testing phase. This would help in identifying usability bugs more clearly and to make our applications bug free, more usable and compatible with the environment of visually challenged people.

\section{REFERENCES}

[1] F. Akhter, M. C. Buzzi, M. Buzzi, B. Leporini, Conceptual Framework, "How to engineer online trust for disabled users," presented at 
IEEE/WIC/ACM International Conference on Web Intelligence and Intelligent Agent Technology - Workshops, 2009.

[2] International Standard Organization (ISO), ISO 9241-11: Ergonomic Requirements for Office Work with Visual Display Terminals (VDTs), Part 11: Guidance on Usability, 1st ed., International Organization for Standardization, Geneva, CH, March 15, 1998.

[3] (October 2012) W3C.WAI-ARIA, [Online]. Available: http://www.w3.org/WAI/intro/aria. php

[4] (October 2012) W3C. Web content accessibility guidelines 2.0. Recommendation [Online]. Available: http://www.w3.org/T R/WCAG20/

[5] B. Leporini, and F. Paternò, "Applying web usability criteria for vision impaired users: does it really improve task performance?" International Journal of Human -Computer Interaction (IJHCI), vol. 24, issue 1, pp. 17-4, January 2008.

[6] J. Nielsen and H. Loranger, Prioritizing Web Usability, CA USA New Riders Publishing. 2006.

[7] (December 2012). Section 508 of the rehabilitation act - USA law [Online]. Available: http://www.section508.gov/

[8] European Union, Communication from the Commission to the European Parliament, the Council, the European economic and social Committee and the Committee of the regions. Towards an accessible information society, [Online]. Available: http://eurlex.europa.eu/LexUriServ/LexUriServ.do?uri=CEL EX:52008DC0804:EN:NOT

[9] H. Petrie, F. Hamilton, and N. King, "Tension, what tension? website accessibility and visual design," in Proc. 2004 International Cross Disciplinary Workshop on Web Accessibility (W4A), ACM Press, April 2008, pp. 13-18.

[10] J. Craven and P. Brophy. (November 2012). Non-visual access to the digital library: the use of digital library interfaces by blind and visually impaired people. Technical report 2004, Manchester: Centre for Research in Library and Information Management (CERLIM), [Online]. Available: http://www.cerlim.ac.uk/pubs/index.php.

[11] M. Y. Ivory, S. Yu, and K. Gronemyer, Search result exploration: a preliminary study of blind and sighted users' decision making and performance," in Extended abstracts of CHI 2004, ACM Press, pp. 1453-1456, 2004.

[12] S. Ray, P. Monangi, Y. Dubey, T. Mukhopadhyay, A. Dubey, S. Chervu, and T. M. Moallem. Panda Braille: a refreshable electro-tactile braille display with no moving parts, [Online]. Available: http://timesofindia.indiatimes.com/india/India-has-largest-blind-popu lation/articleshow/2447603.cms.

[13] J. Nielsen. (September, 2012) Heuristic evaluation. [Online]. Available: www.useit .com/papers/

[14] F. D. D. Mendonca, "A citizen mobile: A case study for blindness," in Proc. 6th International Internet Technology and Secured Transactions (ICITST), pp. 713-717, 2011.
[15] P. G. Fairweather, V. L. Hanson, S. R. Detweiler, and R. S. Schwerdtfeger, "From assistive technology to a web accessibility service," in Proc. International ACM SIGACCESS Conference on Computers and Accessibility, ACM Press, July 8-10, 2002.

[16] P. B. Baxendale, "Man-made index for technical literature-an experiment," IBM Journal of Research and Development, pp. 354-361, Oct 1958.

[17] M. Junji, "Web accessibility technology at the IBM Tokyo research laboratory," IBM Journal of Research and Development, vol. 48, pp. 735-749, Sep. 2004.

[18] D. Bolchini, S. Colazzo, P. Paolini, and D. Vitali, "Designing aural information architectures," in Proc. of the 24th annual ACM international conference on Design of communication, SIGDOC'06, ACM Press, 2006, pp. 51-58.

[19] H. Eichstadt, "Measuring website usability for visually impaired people-a modified GOM analysis," in Proc. International ACM SIGACCESS Conference on Computers and Accessibility, ASSETS 06 , ACM Press, Portland, USA, October 22-25, 2006.

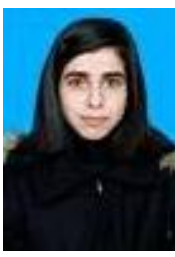

Anam Ashraf got her bachelors' degree in Software Engineering from National University of Modern Languages (NUML), Islamabad, Pakistan in 2011. Currently, she is doing MS Software Engineering in National University of Sciences \&Technology (NUST), Islamabad, Pakistan. She has an experience of over 1 year in the field of Software Testing. Currently, she is working in the capacity of Information Security at Ultra Spectra Pvt. Ltd, Islamabad. Moreover, she had the experience of Quality Testing and Web Designing while working as a Software Quality Test Engineer at Center for Advanced Research in Engineering (CARE) Pvt. Ltd. Here research areas encompass usability engineering and requirements engineering.

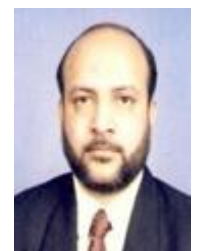

Arif Raza received his M.Sc. (1994) in Computing Science from University of London (U.K.), and PhD (2011) in Software Engineering from the University of Western Ontario (Canada). During his professional career, he has been actively involved in teaching and research. Dr. Raza has authored and co-authored several research articles in peer reviewed journals and conference proceedings. His current research interests, include usability issues in open source software (OSS), human computer interaction, human factors and empirical studies in software engineering. He is presently serving as Assistant Professor at University of Sciences and Technology, Pakistan. 